\title{
Bone and mineral disorders among Saudi diabetics
}

\author{
Muhammad Mahmood Akhtar ${ }^{1 *}$, Abdulaziz Saad Alghamdi², \\ Abdulrahman Mohammed Alshehri ${ }^{3}$, Hussain Zaki Alfaraj ${ }^{4}$, \\ Abdullah Mohammed Alshamrani ${ }^{5}$, Anoud Abdulrazzag Althagafi ${ }^{6}$, \\ Elaf Abdulqader Bahanshel ${ }^{7}$, Muataz Abdulmoghni Aljunaid ${ }^{8}$, Mohammad Abbas AlAjlani', \\ Mohammed Ali Al-Khathami ${ }^{10}$, Mohammed Mana Alqahtani ${ }^{5}$
}

\author{
${ }^{1}$ Department of Internal Medicine, East Jeddah Hospital, Jeddah, Saudi Arabia \\ ${ }^{2}$ Department of Internal Medicine, King Abdullah Hospital, Bishah, Saudi Arabia \\ ${ }^{3}$ Department of Family Medicine, Armed Forces Hospital Southern Region, Khamis Mushait, Saudi Arabia \\ ${ }^{4}$ College of Medicine, Medical University of Lodz, Lodz, Poland \\ ${ }^{5}$ Department of Internal Medicine, Armed Forces Hospital Southern Region, Khamis Mushait, Saudi Arabia \\ ${ }^{6}$ Almojahdeen Primary Health Care, Ministry of Health, Mecca, Saudi Arabia \\ ${ }^{7}$ Department of Internal Medicine, King Fahad Hospital, Jeddah, Saudi Arabia \\ ${ }^{8}$ Department of Internal Medicine, International Medical Center, Jeddah, Saudi Arabia \\ ${ }^{9}$ Department of Internal Medicine, AlQunfudah General Hospital, AlQunfudah, Saudi Arabia \\ ${ }^{10}$ College of Medicine, King Khalid University, Abha, Saudi Arabia
}

Received: 04 April 2021

Accepted: 20 April 2021

\author{
*Correspondence: \\ Dr. Muhammad Mahmood Akhtar, \\ E-mail: h.s.alghamdi@hotmail.com
}

Copyright: (c) the author(s), publisher and licensee Medip Academy. This is an open-access article distributed under the terms of the Creative Commons Attribution Non-Commercial License, which permits unrestricted non-commercial use, distribution, and reproduction in any medium, provided the original work is properly cited.

\begin{abstract}
Increasing bone and mineral changes which caused by both diabetes type 1 and type 2 can raise fracture risks for a period of time during illness and low blood sugar levels. The connection between diabetes and bone fragility is further complicated by the variable effects on the skeleton by various diabetic medications. Diabetic patients are at a higher risk of bone and mineral density alterations, osteoporosis and fragility fractures. Diabetic patients are often susceptible to develop various conditions due to malnutrition, uncontrolled blood sugar and lack of proper follow up regiment. Diabetics should be tested for osteoporosis risk and given effective prevention strategies. Preventing osteoporosis would require interventions such as sufficient vitamin D and calcium intake, physical exercise and exposure to sunlight.
\end{abstract}

Keywords: Diabetes, Bone and mineral density, Saudi Arabia, Complications

\section{INTRODUCTION}

Increasing bone and mineral changes which caused by both diabetes type 1 and type 2 can raise fracture risks for a period of time during illness and low blood sugar levels. The connection between diabetes and bone fragility is further complicated by the variable effects on the skeleton by diabetic medications. ${ }^{1}$ It has been estimated that 1 in 11 worldwide adults has diabetes with a worldwide presence of almost 425 million diabetic patients in adults, which is projected to grow to 629 million by $2045 .^{2}$ Saudi Arabia was reported to be highest country with diabetes mellitus (DM) cases in the middle east region. ${ }^{3} \mathrm{DM}$ can cause calcium homeostasis, skeletal metabolism and bone mass complications due to endocrine and metabolic changes. Bone disease in diabetic patients can be affected through multiple pathways as high body mass index (BMI), fluctuations in insulin levels, higher 
concentrations of advanced glycation end products in collagen, inappropriate homeostatic response of parathyroid hormone secretion, urinary excretion with lower intestinal absorption of calcium, reduced renal function, lower insulin-like growth factor-I, microangiopathy, complex alterations of vitamin D regulation and inflammation. Data on cellular mechanisms and experimental models are extensive, but the relevance for each one of these factors with regards to the clinical situation is unclear. ${ }^{4}$ Glycosuria in diabetic patients decreases bone mineral density (BMD) indirectly via a hypercalciuric effect, resulting in lower serum calcium levels in the body, intensifying bone loss. ${ }^{5}$

Biochemical reactions can be variable as it requires trace elements for stabilization of essential components of enzymes and proteins while it function as cofactors for different enzymes. Certain trace elements control essential biological processes by attaching to the cell membrane's receptor site or by altering the form of the receptor to deter specific molecules from entering the cell. The module of a variety of macro and trace elements is disturbed in type 2 diabetes mellitus (T2DM) and these trace elements play various roles in the pathogenesis and development of T2DM. ${ }^{6}$

Several factors such as renal dysfunction, diabetes medications and a higher rate of falls can raise the risk of fractures in diabetic patients. Osteoporosis is a widespread metabolic bone condition in diabetic patients. Hyperglycemia has been shown to cause adipogenic differentiation, compromised development and increased apoptosis in osteoblasts rather than osteogenesis. ${ }^{7}$ Furthermore, it has been stated that glycemic regulation can help to normalize high bone resorption in poorly regulated diabetes. As a result, proper glycemic regulation in T2DM patients is important for bone health. The connection between diabetes and bone presents an ability to alter bone function in certain anti-diabetic treatments. 8 ,

Diabetic patients are at greater risk at suffering fractures as Vestergaard et al concluded. ${ }^{10}$ In recent research, the consistency of the bone and the possibility of fracture have been detected with T2DM. ${ }^{11}$ More findings suggest that T2DM is linked with lower BMD, with over $50 \%$ osteoporosis. ${ }^{12}$ Increased physical exercise, dietary changes and weight loss have been identified as factors that decreases the incidence of bone disorders among diabetics. The normal treatment for T1DM is aggressive insulin therapy which seems to be related to better skeletal health. ${ }^{13}$ In this paper we will discuss the association between both types of DM and their relation to bone and mineral density alteration in diabetic patients in kingdom of Saudi Arabia.

\section{METHODS}

A systematic search was conducted to identify relevant studies in the following databases was pubmed, medline, web of science, embase, google scholar, and scopus. The following search terms were used (bone), (diabetes or diabetes mellitus), (mineral), (effect or disorder or complication) and (Saudi Arabia). The reference lists were manually searched to identify additional relevant studies meeting inclusion criteria. We included any study that reports the effect of bone and mineral disorders on diabetic patients in Saudi Arabia. No restrictions were applied.

\section{DISCUSSION}

\section{Bone disorders in Saudi diabetics}

A case control study on 104 postmenopausal Saudi women with T2DM and 101 postmenopausal nondiabetic women found that females of T2DM have higher incidence of developing osteoporosis. In the study, the reported mean spine BMD was $0.928 \mathrm{gm} / \mathrm{cm}$ (Tscore $=2.28 \mathrm{SD}$ ) while the mean BMD was $0.817 \mathrm{gm} / \mathrm{cm}$ (T-score=-1.21 SD) for femoral neck in the diabetic group. ${ }^{14}$ Al-Homood et al reported that $29.4 \%$ of diabetic patients were diagnosed with osteoporosis, while $40 \%$ were diagnosed with osteopenia. ${ }^{15}$ Age was a determined risk factor for decreased levels of BMD in patients with osteopenia and osteoporosis. Meanwhile, oral hypoglycemic drugs increased the risk of decreased levels of BMD in osteopenia as well as osteoporosis while vitamin D deficiency increased the risk of osteopenia. AlHariri also reported risk of fractures in diabetic patients and reported that the risk of bones getting affected in diabetic patients can be decreased by early identification and adequate intervention, as necessary. ${ }^{16}$ In Saudi children Khoshhal et al stated that children with T1DM have lower rates of $\mathrm{BMD}$ ( $\mathrm{Z}$ score), poor bone development and elevated markers for bone resorption which can contribute to potential osteoporosis. ${ }^{17}$ In the same study, around $30.8 \%$ of diabetic children had a $\mathrm{Z}$ score below zero from the control group while no children had less than a -1 score. On the other hand, the diabetic group had slightly lower concentrations of osteocalcin and procollagen N-terminal peptides. In addition, serum levels were much higher in the diabetic community of bone resorption markers.

Compared to international figures, Schwartz et al discovered that older diabetic patients lose bone faster than those without DM at all skeletal sites except of the radius. ${ }^{18,19}$ Dubey et al recently reported that women with diabetes had slightly greater BMD loss at the femoral neck but not at other locations when compared to the nondiabetic control group. ${ }^{19}$ Wang et al reported an association of BMD with disease duration and body mass index in elderly men with T2DM, showing a decline in mean BMD parameters among T2DM. ${ }^{20}$ There is also a negative association between BMD parameters and the length of T2DM. Raj et al found a slightly higher rise in BMD among diabetics than non-diabetics of both sexes in different places, as well as high association of young age, 
male gender, elevated body mass index and greater $\mathrm{HbA1c}$ with higher BMD in diabetics. ${ }^{21}$

\section{Mineral disorders in Saudi diabetics}

There is substantial evidence that altered copper $(\mathrm{Cu})$, zinc $(\mathrm{Zn})$, chromium $(\mathrm{Cr})$ and magnesium $(\mathrm{Mg})$ metabolism is closely linked to increased HbA1c levels. These connections may be a risk factor for diabetic complications as reported by Farid and Abulfaraj in a case control study on 55 type 2 diabetic patients and 55 age-matched non-diabetic healthy subjects. ${ }^{22}$ Significantly higher $\mathrm{Cu}$ levels $\mathrm{p}<0.001$, lower $\mathrm{Zn}$ levels $(\mathrm{p}<0.05)$ and also lower $\mathrm{Cr}, \mathrm{Mg}$ levels $(\mathrm{p}<0.05)$ in patients with DM in comparison with healthy subjects were reported. Statistical analysis showed a positive correlation between serum levels of $\mathrm{Cu}$ and $\mathrm{Zn}$ in the group of healthy subjects $(\mathrm{p}<0.0001)$. Patients with DM had altered metabolism of $\mathrm{Zn}, \mathrm{Cu}, \mathrm{Cr}, \mathrm{Mn}$, and $\mathrm{Mg}$ and this may be related to increased values of glycated hemoglobin.

Internationally, recent research has shown that serum levels of certain minerals are lower in diabetic patients than in controls, especially in poorly regulated diabetes. $^{22,23}$ Many other researches has indicated that metabolic disruptions associated with insulin resistance and hyperglycemia can result in mineral deficiency. ${ }^{24,25}$ Diabetes according to Dubey et al can alter trace element concentrations, which can result in changes in an individual's nutritional status. ${ }^{19}$ While certain micronutrients are believed to be implicated in the pathogenesis and development of diabetes mellitus, others can only be a result of glucose aversion and insulin resistance that is depleted or altered. Certain elements, such as $\mathrm{Cu}, \mathrm{Fe}$ and $\mathrm{Se}$ can be more abundant in diabetic patients' serum or tissues than in controls.

\section{BMI and BMD}

Previous studies suggested a positive relationship between BMI and BMD levels. Generally, patients with low BMI $\left(<18.5 \mathrm{~kg} / \mathrm{m}^{2}\right)$ have reduced BMD levels and thus, low T-scores, hence, they are categorized as osteopenic or osteoporotic. ${ }^{26}$ In Saudi Arabia Hariri et al found positive relationship between BMI and BMD Tscores in the hip and spine regions. ${ }^{27}$ Low BMI could be a risk factor for osteoporosis, whereas normal/high BMI could be protective against osteoporosis among adults with diabetes. In accordance with these findings, Schwartz et al discovered that for a given $\mathrm{T}$-score and age, the fracture frequency was greater in T2D patients than in non-diabetics. ${ }^{18}$ Furthermore, a T-score in a diabetic woman is correlated with hip fracture risk equal to a $\mathrm{T}$-score in a non-diabetic woman with a T-score roughly 0.5 unit lower. ${ }^{28}$ Nonetheless, data clearly show that BMD consistently underestimates fracture risk, it also stratifies fracture risk in diabetic elderly patients. ${ }^{29}$ Dutta $\mathrm{Mk}$ et al reported significant positive correlation was found between spine BMD and BMI ( $\mathrm{r}=0.372$, $\mathrm{p}=0.002)$, total cholesterol $(\mathrm{r}=0.272, \mathrm{p}=0.026)$, lowdensity lipoprotein $(\mathrm{r}=0.242, \mathrm{p}=0.047)$ and triglycerides $(\mathrm{r}=0.282, \mathrm{p}=0.021){ }^{30}$ There was no correlation between BMD and glycosylated hemoglobin $(r=0.158, p=0.265)$.

\section{Vitamin D level and diabetes}

Despite a strong correlation with parathormone levels, the effect of vitamin D deficiency was only seen in osteopenic patients, which may be explained by the fact that some of the osteoporotic patients were supplemented with vitamin D preparations. In Saudi Arabia, diabetic patients were deficient in vitamin D regardless of DM status, showing a stronger need for vitamin D supplementation. The mean levels of serum $25-\mathrm{OH}$ vitamin $\mathrm{D}$ is $15.7+7.5 \mathrm{ng} / \mathrm{ml}$ in diabetics, compared to a normal $11.1+5.9 \mathrm{ng} / \mathrm{ml}$ in non-diabetic population and a total of $340(98.5 \%)$ patients in both groups were found to be deficient in $25-\mathrm{OH}$ vitamin D. ${ }^{30}$ According to a cross sectional study by Al-Homood et al advanced age and vitamin $\mathrm{D}$ deficiency are factors that assess BMD reduction as they can improve BMD rates. ${ }^{15}$ In comparison to these results, Kota et al reported no causal link between vitamin D levels and BMD, including a substantial correlation with parathormone levels. ${ }^{31}$ Also, Sultan et al reported higher ALP and PTH in both diabetic groups than in controls, but lower serum calcium, $25 \mathrm{OH}-\mathrm{D}$ and osteocalcin than those in control group. ${ }^{32}$ Urinary calcium and urinary Dpd were also higher in the control group.

\section{CONCLUSION}

Diabetic patients are at a higher risk of bone and mineral density alterations, osteoporosis and fragility fractures. Diabetics should be tested for osteoporosis risk and given effective prevention strategies. Preventing osteoporosis would require interventions such as sufficient vitamin D and calcium intake, physical exercise and exposure to sunlight.

\section{Funding: No funding sources \\ Conflict of interest: None declared \\ Ethical approval: Not required}

\section{REFERENCES}

1. Ferrari SL, Abrahamsen B, Napoli N, Akesson K, Chandran M, Eastell R, et al. Diagnosis and management of bone fragility in diabetes: an emerging challenge. Osteoporo Int. 2018;29(12):2585-96.

2. Saeedi P, Petersohn I, Salpea P, Malanda B, Karuranga S, Unwin N, et al. Global and regional diabetes prevalence estimates for 2019 and projections for 2030 and 2045: results from the international diabetes federation diabetes atlas. Diabet Res Clin Pract. 2019;157:107843.

3. Wild S, Roglic G, Green A, Sicree R, King H. Global prevalence of diabetes: estimates for the year 
2000 and projections for 2030. Diabetes Care. 2004;27(5):1047-53.

4. Isidro ML, Ruano B. Bone disease in diabetes. Current Diabet Rev. 2010;6(3):144-55.

5. Pittas AG, Lau J, Hu FB, Dawson-Hughes B. The role of vitamin $\mathrm{D}$ and calcium in type 2 diabetes: a systematic review and meta-analysis. J Clinic Endocrinol Metabol. 2007;92(6):2017-29.

6. Young VR. Trace element biology: the knowledge base and its application for the nutrition of individuals and populations. $\mathrm{J}$ Nutrit. 2003;133:1581-7.

7. Wang W, Zhang X, Zheng J, Yang J. High glucose stimulates adipogenic and inhibits osteogenic differentiation in MG-63 cells through cAMP/protein kinase A/extracellular signalregulated kinase pathway. Molecul Cell Biochem. 2010;338(1-2):115-22.

8. Okazaki R, Totsuka Y, Hamano K, Ajima M, Miura M, Hirota Y, et al. Metabolic improvement of poorly controlled noninsulin-dependent diabetes mellitus decreases bone turnover. J Clinic Endocrinol Metabol. 1997;82(9):2915-20.

9. Vianna AGD, Sanches CP, Barreto FC. Review article: effects of type 2 diabetes therapies on bone metabolism. Diabetol Metabol Syndr. 2017;9(1):75.

10. Vestergaard P, Rejnmark L, Mosekilde L. Diabetes and its complications and their relationship with risk of fractures in type 1 and 2 diabetes. Calcif Tissue Int. 2009;84(1):45-55.

11. Farr JN, Khosla S. Determinants of bone strength and quality in diabetes mellitus in humans. Bone. 2016;82:28-34.

Strotmeyer ES, Cauley JA, Orchard TJ, Steenkiste AR, Dorman JS. Middle-aged premenopausal women with type 1 diabetes have lower bone mineral density and calcaneal quantitative ultrasound than nondiabetic women. Diabetes Care. 2006;29(2):306-11.

12. Campos PMM, López-Ibarra PJ, Escobar-Jiménez F, Serrano Pardo MD, García-Cervigón AG. Intensive insulin therapy and bone mineral density in type 1 diabetes mellitus: a prospective study. Osteopor Int. 2000;11(5):455-9.

13. Al-Maatouq MA, El-Desouki MI, Othman SA, Mattar EH, Babay ZA, Addar M. Prevalence of osteoporosis among postmenopausal females with diabetes mellitus. Saudi Med J. 2004;25(10):1423-7.

14. Al-Homood IA, Sheshah I, Mohammed AGA, Gasim GI. The prevalence and risk factors of osteoporosis among a Saudi female diabetic population. Open Acc Maced J Med Sci. 2017;5(2):177-81.

15. Al-Hariri M. Sweet bones: the pathogenesis of bone alteration in diabetes. J Diabet Res. 2016:6969040.

16. Khoshhal KI, Sheweita SA, Al-Maghamsi MS, Habeb AM. Does type 1 diabetes mellitus affect bone quality in prepubertal children? J Taibah Univ Med Sci. 2015;10(3):300-5.

17. Schwartz AV, Ewing SK, Porzig AM, McCulloch CE, Resnick HE, Hillier TA, et al. Diabetes and change in bone mineral density at the hip, calcaneus, spine, and radius in older women. Front Endocrinol. 2013;4:62.

18. Dubey P, Thakur V, Chattopadhyay M. Role of minerals and trace elements in diabetes and insulin resistance. Nutrients. 2020;12(6):1864.

19. Wang X, Pei Y. Correlation of bone mineral density with disease duration and body mass in elder men with type 2 diabetes mellitus. Chin J Tissue Engine Res. 2007;27(2):190-7.

20. Raj S, Baiju S, Vijayan R, Rajan G. Association between Bone Mineral Density and Type 2 Diabetes Mellitus-an original. Brit J Res. 2014;1(2):63-7.

21. Farid SM, Abulfaraj TG. Trace mineral status related to levels of glycated hemoglobin of type 2 diabetic subjects in Jeddah, Saudi Arabia. Med J Islamic World Aca Sci. 2013;109(892):1-10.

22. DiSilvestro RA. Zinc in relation to diabetes and oxidative disease. J Nutrit. 2000;130(5):1509-11.

23. Kazi TG, Afridi HI, Kazi N, Jamali MK, Arain MB, Jalbani N, et al. Copper, chromium, manganese, iron, nickel, and zinc levels in biological samples of diabetes mellitus patients. Biolog Trace Elem Res. 2008;122(1):1-18.

24. Huerta MG, Roemmich JN, Kington ML, Bovbjerg VE, Weltman AL, Holmes VF, et al. Magnesium deficiency is associated with insulin resistance in obese children. Diabetes Care. 2005;28(5):1175-81.

25. Mellits D. Diagnosis and classification of diabetes mellitus. Diabetes Care. 2005;28(37):5-10.

26. Hariri AF, Almatrafi MN, Zamka AB, Babaker AS, Fallatah M, Althouwaibi $\mathrm{OH}$, et al. Relationship between body mass index and T-Scores of bone mineral density in the hip and spine regions among older adults with diabetes: a retrospective review. J Obesit. 2019:9827403.

27. Schwartz AV, Vittinghoff E, Bauer DC, Hillier TA, Strotmeyer ES, Ensrud KE, et al. Association of BMD and FRAX score with risk of fracture in older adults with type 2 diabetes. JAMA. 2011;305(21):2184-92.

28. Schacter GI, Leslie WD. DXA-based measurements in diabetes: can they predict fracture risk? Calcified Tissue Int. 2017;100(2):150-64.

29. Alhumaidi M, Agha A, Dewish M. Vitamin D deficiency in patients with type-2 diabetes mellitus in southern region of Saudi Arabia. Maedica. 2013;8(3):231-6.

30. Kota S, Jammula S, Kota S, Meher L, Modi K. Correlation of vitamin $\mathrm{D}$, bone mineral density and parathyroid hormone levels in adults with low bone density. Ind J Orthopaed. 2013;47(4):402-7.

31. Sultan E, Taha I, Saber LM. Altered bone metabolic markers in type 2 diabetes mellitus: impact of glycemic control. J Taibah Univer Med Sci. 2008;3(2):104-16.

Cite this article as: Akhtar MM, Alghamdi AS, Alshehri AM, Alfaraj HZ, Alshamrani AM, Althagafi AA, et al. Bone and mineral disorders among Saudi diabetics. Int J Community Med Public Health 2021;8:2605-8. 